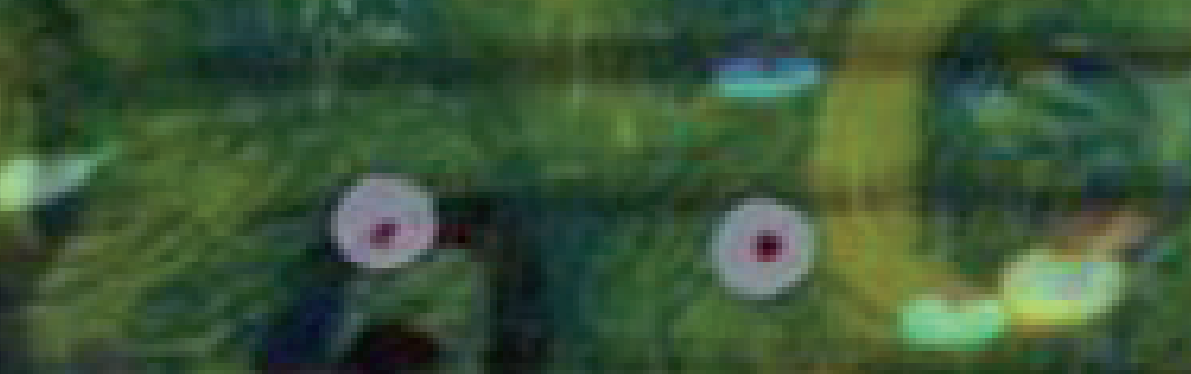

[a.

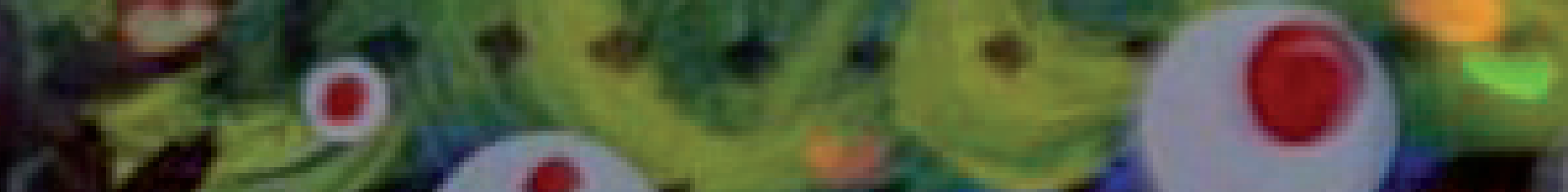

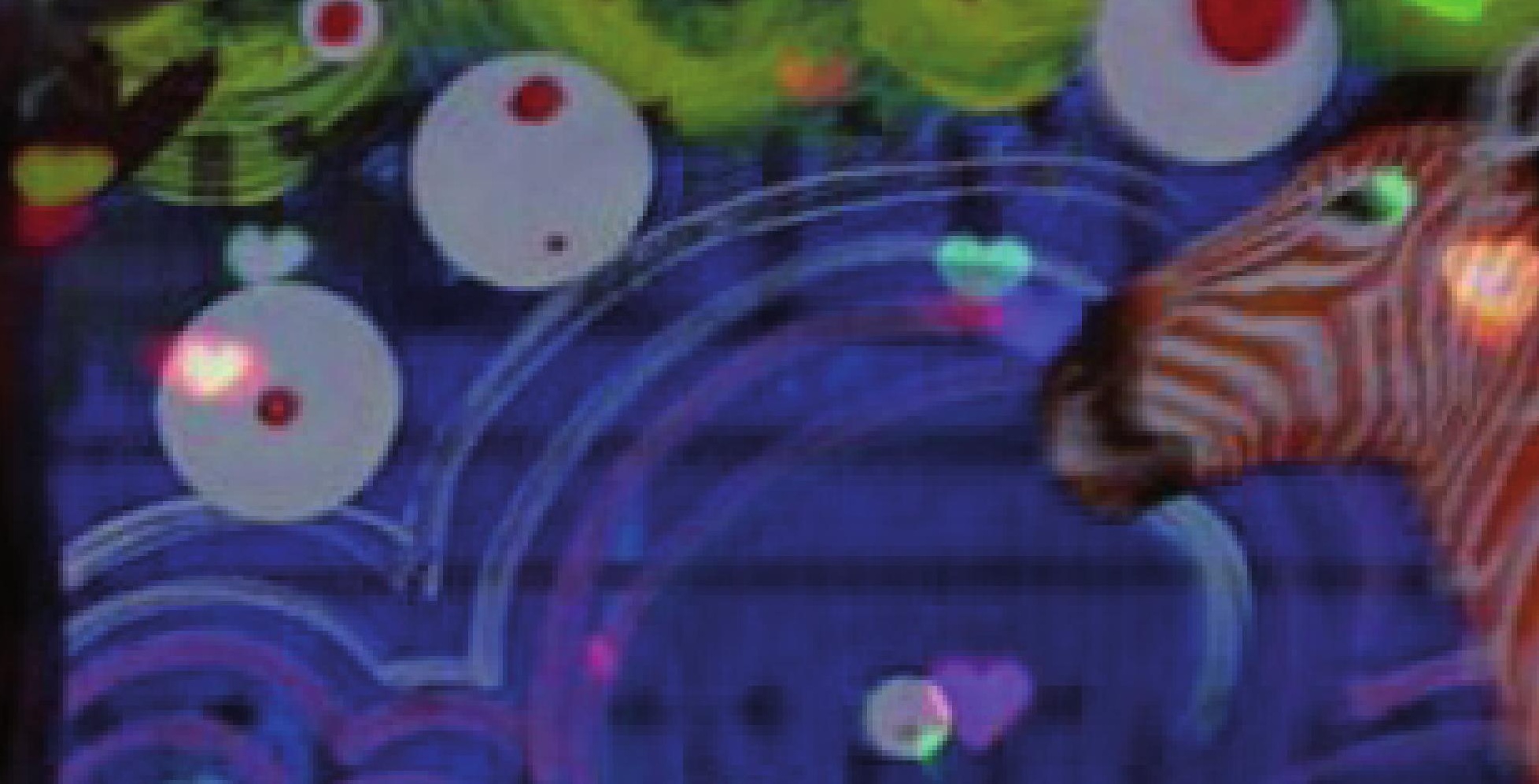

2

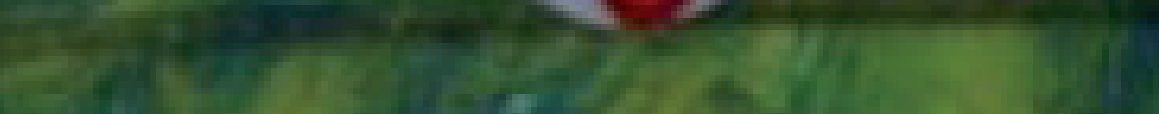

N4t 


\section{RECONOCIMIENTO DEL CUERPO DESDE LA EDUCACIÓN EN SEXUALIDAD EN LOS ESTUDIANTES DE SÉPTIMO DEL COLEGIO VILLEMAR EL CARMEN IED}

\section{Recognition of the body since sexuality education in seventh students of the School Villemar el Carmen IED}

Fecha de recepción: 29 de mayo de 2015

Fecha de aprobación: 03 de septiembre de 2015

Luz Adriana Prieto Cárdenas ${ }^{1}$

\section{Resumen}

Este trabajo es el resultado de la práctica de intervención pedagógica e investigativa realizada en el año 2014, en el Colegio Villemar el Carmen IED, con los estudiantes de 705, jornada mañana. El problema investigativo se construyó a partir de los intereses e inquietudes que presentó el grupo de estudiantes respecto a su cuerpo y su sexualidad. El objetivo principal que guio esta investigación fue analizar la incidencia de la educación en sexualidad en el reconocimiento del cuerpo de los estudiantes de séptimo del Colegio Villemar el Carmen IED.

El paradigma empleado fue el cualitativo-interpretativo; se centró en las visiones y lógicas de pensar y hacer de los estudiantes, en relación con el cuerpo y la sexualidad. Para lograr la interpretación de esa realidad, las técnicas e instrumentos empleados fueron la observación participante, los registros de observación, el registro fotográfico y talleres sobre sexualidad.

Se concluye que la educación en sexualidad es vital en la escuela, porque parte del reconocimiento del sujeto, de su cuerpo, de sus sentimientos y emociones, así como de sus creencias adquiridas culturalmente, como base del quehacer pedagógico. Concibiendo el cuerpo como un entramado múltiple de dimensiones que trasciende lo biológico, ya que contempla lo psicológico y lo cultural.

Palabras clave: Reconocimiento del cuerpo, educación en sexualidad, concepciones, cuerpo y sexualidad.

\section{Abstract}

This work is the result of the practice of teaching and research intervention made in 2014, in the School Villemar el Carmen IED, with the students of 705, morning shift. The research problem was constructed from the interests and concerns presented by the group of students about their bodies and sexuality. The main objective that guided this research was analyze the impact of sexuality education in the recognition of the body of the seventh students of the School Villemar el Carmen IED.

The paradigm used was the qualitative-interpretive; it focuses on the visions and logical thinking and make of the students, in relation to the body and sexuality. To achieve the interpretation of that reality, the techniques and instruments used were participant observation, observation records, the photographic record and workshops on sexuality.

It is concluded that sexuality education in school is vital, because of the recognition of the subject, your body, your feelings and emotions, as well as culturally acquired beliefs, as basis for pedagogical work. Conceiving the body as a multi-dimensional framework that transcends the biological, and that includes the psychological and the cultural.

Key words: Recognition of the body, sexuality education, conceptions, body and sexuality.

1 Estudiante: línea de investigación: “Configuración de los conocimientos acerca de lo vivo y de la vida en contextos culturalmente diversos". Correo electrónico: luzaprieto025@hotmail.com 


\section{Introducción}

En general, la educación en sexualidad ha encaminado sus esfuerzos a vincular el cuerpo y la sexualidad con la genitalidad, la enfermedad y la reproducción, haciendo uso de metodologías que se restringen a ofrecer información sobre los métodos anticonceptivos, el uso apropiado del preservativo y la prevención de las infecciones de transmisión sexual. De esta manera, cuando la temática se ofrece en la escuela, según Morgade (2008), es por lo general en el componente de ciencias naturales o biología:

Ahora bien sabemos que el abordaje en esas áreas se ha limitado a la anatomía y la fisiología de la genitalidad, y al estudio de los riesgos de contraer ITS o de embarazos no planeados: una visión de la sexualidad reducida y, por lo general, desubjetivada. (Morgade, 2008, p. 11).

Siguen silenciadas la dimensión cultural que atraviesa la "materialidad" de la dotación biológica, la afectividad y las emociones que se vinculan con el uso, disfrute y respeto del propio cuerpo y del cuerpo de otros u otras, las sexualidades no hegemónicas, el "sujeto" de los derechos sexuales, la historicidad de las formas de organización vincular y otros temas que suelen interesar a chicos y chicas puestos a preguntar/se respecto de la sexualidad en un sentido integral que la perspectiva de género habilita. (Morgade, 2008, p. 12).

No obstante, como investigadora, considero que la educación en sexualidad dirigida a la comunidad estudiantil significa compartir que la vida sucede en un cuerpo, pero además formar en valores, sentimientos y actitudes positivas frente a la sexualidad que transformen las creencias y tabús frente al tema, prioridades que parecen ser restringidas a las finalidades de la escuela.

En varios maestros prevalece un sentimiento de impotencia e incertidumbre al no saber cómo abordar en la escuela las situaciones relacionadas con el cuerpo y con la sexualidad, ya que afrontan grandes dilemas personales y profesionales referentes a ¿cuáles son los contenidos apropiados para una educación en sexualidad que promueva el reconocimiento del cuerpo?, ¿cómo influye su historia de vida a la hora de educar en sexualidad?, ¿de qué hablamos cuando pensamos en cuerpo y en educación en sexualidad?, ¿podemos hablar de sexualidad como componente biológico, psicológico y cultural?. Asimismo, son pocos los escritos que encaminan el quehacer pedagógico de los maestros y maestras en materia de educación en sexualidad.

De esta manera, la pregunta problema que guio esta investigación fue ¿cómo incide la educación en sexuali- dad en el reconocimiento del cuerpo de los estudiantes de séptimo del Colegio Villemar el Carmen IED? Teniendo en cuenta lo anterior, el objetivo principal de este trabajo fue analizar la incidencia de la educación en sexualidad en el reconocimiento del cuerpo de los estudiantes de séptimo del Colegio Villemar el Carmen IED. Se consiguió a partir de unos objetivos específicos que dieron respuesta a la investigación en general (identificar las concepciones en torno al cuerpo y la sexualidad en los estudiantes de séptimo del Colegio Villemar el Carmen IED, para de esta forma desarrollar talleres sobre sexualidad en los que se relacionen los constructos teóricos respecto al cuerpo y la sexualidad con sus realidades y vivencias, y por ende, contribuir al reconocimiento de su cuerpo desde la educación en sexualidad).

Por un lado, como maestra en formación, considero importante la presente investigación para el campo de la educación en sexualidad, porque se construyó a partir de los intereses e inquietudes que presentaron los estudiantes de séptimo del Colegio Villemar el Carmen IED respecto a su cuerpo y su sexualidad. Para ello, como propuesta para abordar tal educación en sexualidad, se elaboraron una serie de talleres, cada uno de los cuales contaron con una dinámica y recopilaron las concepciones de los estudiantes sobre el tema abordado, cabe aclarar que las concepciones se entenderán de acuerdo con Tamayo (2004), como "las nociones que los estudiantes traen consigo antes del aprendizaje formal de una determinada materia" (p. 17). A la vez, dichos talleres no solo tuvieron un enfoque biológico, sino que incluyeron perspectivas psicológicas y culturales de los sujetos que fueron objeto de estudio, se constituyeron así en parte de una investigación que intenta aportar a las prácticas de educación en sexualidad.

Por otro lado, se pretendió que esta investigación lograra contribuir a la línea de investigación "Configuración de los conocimientos acerca de lo vivo y de la vida en contextos culturalmente diversos", en la construcción de nuevas posturas que surgen de la escuela, orientadas a implicar al educando y a favorecer la comprensión de la educación en sexualidad desde la vida misma, ya que en el proceso de enseñanza-aprendizaje ningún conocimiento es más que otro, sino que esos conocimientos que surgen de la experiencia y los que se construyen desde el ámbito académico se deben compartir y combinar a través del diálogo, lo que permite que se aporte a la enseñanza de la biología en general.

Tal experiencia investigativa aportó a mi formación como maestra de biología, ya que me permitió conseguir experiencia: en cuanto a la construcción y puesta en práctica de una investigación, proyectada a partir de una proble- 
mática específica, pensada para contribuir al campo de la educación. Además, los educandos de grado séptimo del Colegio Villemar el Carmen IED, desde sus experiencias impregnadas por el contexto, permitieron conocer sus distintas concepciones respecto a su cuerpo y su sexualidad, en aras de la reflexión y acción, en colectividad.

\section{Antecedentes}

Se realizó una revisión documental de trabajos de grado y revistas científicas en los que se han elaborado escritos respecto al reconocimiento del cuerpo por parte de los sujetos y en relación a la sexualidad. Dentro de estas investigaciones se halló que este es un contenido de enseñanza con una indagación escasa, que cuando se efectúa, la mayoría de veces se hace de forma holística, pues se lleva a cabo una relación directa entre el reconocimiento del cuerpo y la sexualidad.

Dentro de dichos trabajos se puede mencionar el de Quijada (2010), que expone una forma de comprender las percepciones del cuerpo y la sexualidad que presentan mujeres de diferentes niveles socioeconómicos y de distintas generaciones en Santiago de Chile. Para ello, la metodología utilizada por la autora fue de carácter cualitativo y exploratorio, a través de la cual se abordaron de manera comprensiva las percepciones que las mujeres tenían de su cuerpo y las percepciones que tenían de su vida sexual. Dado el carácter del problema de investigación, la técnica de recolección de información que uso fue la entrevista en profundidad abierta. La autora en su tesis llega a las siguientes conclusiones:

Las mujeres de este estudio, de niveles socioeconómicos bajos y medios-bajos, perciben su cuerpo de forma distinta y viven su sexualidad de forma similar. [...] En su totalidad, las mujeres tienen desconocimiento de su cuerpo, especialmente con la función y aspectos de sus genitales.

Las mujeres no se sienten conformes con su cuerpo y por cierto le cambiarían algo, lo que nos devela que el cuerpo es percibido estéticamente, en cuanto este tiene que cumplir los cánones socialmente establecidos de belleza, delgadez, entre otros y por el contrario, no se sienten bien con su cuerpo, se sienten gordas, envejecidas, etc. (Quijada, 2010, p. 87).

En el anterior trabajo se evidencia que, desde las percepciones de su cuerpo, el grupo de mujeres del estudio logró llegar a su reconocimiento y, a la vez, contribuir a la configuración de su sexualidad que hace parte de su diario vivir en un contexto específico. Sin embargo, cabe resaltar que en otras investigaciones que se realicen, el cuerpo no solo debe ser reconocido desde el punto de vista biológico, pues también está atravesado por aspectos psicológicos y culturales.

El artículo científico elaborado por Salim, Araújo y Gualda (2010), "Cuerpo y sexualidad: experiencias de puérperas", permite conocer como las mujeres se relacionan con la sexualidad y los cambios corporales en el periodo del puerperio. La metodología empleada por las autoras fue cualitativa y los métodos adoptados para la recolección de datos fueron la observación y la entrevista semiestructurada. Seis mujeres del oeste del estado de São Paulo participaron del estudio. Las autoras en su artículo llegan a las siguientes conclusiones: "la perspectiva que se puede obtener sobre la mujer durante el puerperio debe ser amplia; se debe escuchar sus dificultades y vivencias, conocer el contexto cultural y social en el que ella vive para que el cuidado suceda" (Salim et al., 2010, p. 17).

En la investigación preliminar se evidencia que, a partir de las experiencias y cambios que vivenciaron en torno a su cuerpo el grupo de mujeres del estudio, llegaron a su reconocimiento, en cuanto, a lo que respecta a su sexualidad se relacionó con las dificultades, miedos y preocupaciones que presentaron durante ciertas etapas de su vida. De esta manera, en otras indagaciones que se lleven a cabo es esencial partir de la dimensión psicológica del sujeto al conocer sus preocupaciones, dificultades y miedos respecto a su cuerpo e incluir la dimensión biológica al explorar sus cambios físicos y fisiológicos en relación al cuerpo.

Por último, Insaurralde (2013) muestra una manera de recuperar las representaciones que se conforman alrededor del cuerpo y la sexualidad por parte de los jóvenes, que la sociedad ubica en categorías de género y suponen roles, expectativas y condiciones. Por ende, la metodología empleada por la autora fue de tipo cualitativa. El trabajo de campo fue realizado en una escuela media pública ubicada en la zona periurbana de la ciudad de La Plata. Luego, se realizaron entrevistas en profundidad a jóvenes varones y mujeres de entre 17 y 19 años que asistían al colegio seleccionado. La autora llega a las siguientes conclusiones:

La familia constituye un espacio abierto y disponible a interceptar las inquietudes de los y las jóvenes, pero es donde aún persisten modelos de feminidad y masculinidad que resguardan el cuerpo femenino y exaltan el cuerpo masculino en lo que respecta a la sexualidad. (Insaurralde, 2013, p. 108). 
En el trabajo mencionado se evidencia que, en el grupo de jóvenes del estudio, la familia incide directamente en el reconocimiento de su cuerpo y en su educación en sexualidad, pues es la primera institución que transmite valores, miedos y mitos en torno al tema. Cabe tener en cuenta que tales vínculos suponen presión sea para la iniciación sexual -en el caso de los hombres - o para la postergación de la misma -en el caso de las mujeres-.

Cada uno de los estudios presentados anteriormente se relacionan con los objetivos de la presente investigación de la siguiente forma: el trabajo de Quijada (2010), "Percepciones que las mujeres tienen de su cuerpo y vivencia sexual", al igual que la presente investigación, parte de las concepciones de los sujetos implicados en el estudio, con el propósito de llegar al reconocimiento del cuerpo desde la educación en sexualidad, lo que permite evidenciar que al partir de las nociones de los educandos en relación con su cuerpo así como su sexualidad y relacionarlas con constructos teóricos, se puede trascender respecto a las visiones que tales sujetos poseen, en torno a dicho tema a nivel biológico, y aunque no lo incluye Quijada en su estudio, también se puede trascender a nivel psicológico y cultural. Por su parte, la investigación de Salim et al. (2010) tiene relación con la presente investigación, porque parte de las experiencias que poseen los sujetos del estudio en relación con sus preocupaciones, miedos y cambios que han evidenciado en torno a sus cuerpos, de la misma forma, que lo hacen los estudiantes de séptimo del Colegio Villemar el Carmen IED en el transcurso de este trabajo, lo que probablemente influye en el reconocimiento de su propio cuerpo. Por último, el trabajo de Insaurralde (2013), "Sexualidad, cuerpo y género: las representaciones de jóvenes pobres de la ciudad de La Plata", se asemeja a uno de los objetivos de la presente investigación, pues dicha autora recupera las representaciones que se conforman alrededor del cuerpo y la sexualidad por parte de los jóvenes que seleccionó para su estudio, al igual que en este trabajo se identifican las concepciones de los estudiantes de séptimo del Colegio Villemar el Carmen IED en torno al cuerpo y la sexualidad, teniendo como meta desde la educación en sexualidad el reconocimiento del cuerpo.

\section{Referentes teóricos}

En el presente trabajo se efectuó una consulta de los conceptos centrales que hacen parte de la problemática que guía esta investigación. En este caso, se tuvieron en cuenta los constructos teóricos, en los que las nociones a investigar fueron educación en sexualidad, concepciones, cuerpo y sexualidad.
Desde esta perspectiva se evidencia cómo el tema del cuerpo y la sexualidad en general es de gran preocupación, hablar sobre dicho contenido en la escuela no solo implica brindar conocimientos para la prevención de embarazos e infecciones de transmisión sexual, sino que supone formar en valores, sentimientos y actitudes positivas frente al cuerpo y la sexualidad que transformen las creencias y tabús que poseen los estudiantes.

Así, al referirse a la educación en sexualidad se hace énfasis en el reconocimiento del sujeto, de su cuerpo, de sus sentimientos, emociones y creencias adquiridas culturalmente. Por tal motivo, Barragán asegura que

La educación en sexualidad es un proceso lento, gradual y complejo que hace posible la construcción de las diferentes nociones sexuales, ayuda a comprender los procesos históricos y culturales, por los que se han generado los conocimientos actuales, la organización social y sexual vigentes. (2000, p. 19).

De acuerdo con Conill:

La educación en sexualidad constituye un complejo fenómeno social que posibilita la asimilación de los patrones históricos y culturales que circundan al individuo y que deben integrarse armónicamente al desarrollo de su personalidad; es por ello que no se puede ver desligada del contexto social, familiar y escolar, es precisamente en estos espacios donde se conforma, educa y evalúa la sexualidad dados los niveles de desempeño, interacción y comunicación que en ellos se establecen. (2005, p. 2).

Las visiones preliminares en la investigación permiten repensar la educación en sexualidad como una necesidad que nos solicitan los niños y niñas, en este caso, los estudiantes de séptimo del Colegio Villemar el Carmen IED, para reconocerse primero como sujetos, reconocer su propio cuerpo y reconocer a los demás. Incumbe a madres, padres y maestros de todas las áreas, no solo de biología, no decepcionarlos, hablarles abiertamente del tema, con afecto, respeto y comunicación honesta que permita la seguridad respecto a la toma de decisiones así como la libre expresión de necesidades y de opiniones sobre el propio cuerpo y la sexualidad frente a las ideas dominantes en el ámbito sociocultural.

En cuanto a la construcción del conocimiento en torno a la educación en sexualidad, es primordial la interacción dentro de un contexto social y cultural, ya que esta construcción no es fruto de una actividad solitaria, sino que esta mediada por la influencia social. Por ende, en dicha 
construcción, se ponen en juego las concepciones que tiene cada persona frente a la realidad. En esta perspectiva, según Tamayo (2004), "las concepciones se refieren a las nociones que los estudiantes traen consigo antes del aprendizaje formal de una determinada materia" ( $p$. 17). De acuerdo con Giordan y Vecchi: "Las concepciones son entendidas como el proceso de una actividad de construcción mental de lo real, que se elabora de la información percibida del entorno, información que es codificada, organizada y categorizada y permite conformar un todo coherente" (1995, p. 111). Por último, Vilanova, Mateos y García aseguran que "las concepciones se entienden como las ideas de carácter intuitivo que poseen los sujetos respecto de los procesos, las condiciones y los resultados involucrados en la enseñanza y el aprendizaje" (2011, p. 55).

Las anteriores perspectivas en este trabajo permiten establecer, con respecto a los maestros de biología, que a la hora de enseñar cualquier tema, en este caso al hablar sobre la sexualidad y el cuerpo, se hace necesario primero identificar las concepciones de los estudiantes, ya que son los conocimientos con que los estudiantes interpretan y explican los hechos y fenómenos naturales que los rodean, y no pueden ir desligados de los constructos teóricos que se les van a compartir desde la educación en sexualidad.

El cuerpo ha sido entendido como una construcción social que identifica a cada sujeto y a su vez está atravesado por factores psicológicos y biológicos. Por ende, el cuerpo es pensado por Braidotti como "una entidad socializada, codificada culturalmente, que constituye el sitio de intersección, de lo biológico, lo social y lo lingüístico" (2004, p. 20). De acuerdo con Quijada:

Cuerpo es una construcción social y por tanto constituye un objeto de investigación a través del cual podemos observar y conocer nuestra identidad, dado que es el lugar donde se expresan los signos de nuestra condición social. Expresa nuestras formas de vivir y de pensar. (2010, p. 47).

Los anteriores puntos de vista en la investigación permiten visibilizar, con respecto a los maestros de biología, que al educar en sexualidad en la escuela se debe brindar al estudiante la oportunidad para que primero se reconozca como sujeto, reconozca a los demás y principalmente reconozca su cuerpo a partir de diversas dimensiones tales como la biológica, la psicológica y la cultural, tal es el caso de los estudiantes de séptimo del Colegio Villemar el Carmen IED.
Por último, la sexualidad ha sido concebida como un entramado de manifestaciones, expresiones y dimensiones, como la biológica, la psicológica y la cultural, que están presentes en todas las etapas de la vida. Así, la sexualidad es asumida por González y Castellanos como

Una compleja expresión de la individualidad que está ligada al desarrollo del sujeto. Tiene como punto de partida el sexo, está relacionada con el placer, con lo erótico, con la reproducción; pero va más allá, está vinculada a las relaciones interpersonales, a los sentimientos y a la identidad del ser humano. (1998, p. 7).

De acuerdo con Azcuy:

Es una configuración psicológica de la personalidad, que se conforma y desarrolla a partir de la interacción sistémica de premisas biológicas y sociales que en ella intervienen, expresando de forma personalizada las vivencias afectivas, las actitudes, los conocimientos y modos de actuación que el individuo interioriza activamente a partir de la cultura construida en el contexto socio histórico en el que vive y se desarrolla. (2001, p. 24).

Según González, Duque, Gladys, Ramírez, Otelo y Marín:

Es algo natural y necesario para todos; en la necesidad de comunicarnos placenteramente, tiene que ver con lo que pensamos de nosotros y de los demás, de la reflexión que hayamos hecho de nuestro comportamiento y nuestros pensamientos. Esta es la suma de ternura, fantasía, ideales, placer, alegría, comunicación e intimidad. Estos aspectos se presentan vivos desde la infancia hasta la vejez. (2011, p. 10).

Dichas perspectivas en la investigación permiten pensar la sexualidad desde un enfoque integral, ya que no solo se concibe la sexualidad como una cualidad propia del ser humano constituida exclusivamente por factores biológicos, pues la sexualidad los trasciende al configurarse también por factores psicológicos y factores culturales, que están presentes a lo largo de toda la vida y desde los cuales se puede llegar al reconocimiento del cuerpo.

\section{Materiales y métodos}

Esta investigación de práctica pedagógica surgió de mis intereses y motivaciones como maestra, así como de los intereses de la población seleccionada, en este caso, los estudiantes de grado 705, jornada mañana, del Colegio Villemar el Carmen IED, los cuales se encaminaron en torno a inquietudes que presentaron, por ejemplo, desde la dimensión biológica manifestaron preguntas como: 
¿Por qué el hombre tiene erección cuando ve a una mujer linda?, ¿qué cambios físicos se experimentan?, ¿se cambia desde los 10 años?, ¿por qué al hombre le sale semen?, ¿por qué cambia la voz?, ¿por qué a las mujeres les da la menstruación?, ¿por qué a las mujeres les crecen los senos?, ¿por qué el hombre se masturba?, ¿por qué las mujeres se masturban?, ¿qué es el placer sexual?, ¿por qué se da el acné, sin que se coma grasa?, ¿por qué sale el vello púbico?, ¿a todos los hombres les sale la manzana de adán?, ¿por qué el cuerpo de las mujeres es diferente al de los hombres?, ¿por qué me salen vellos en el cuerpo?, ¿por qué nos crece a los hombres la parte íntima?, ¿por qué a las mujeres se les ensancha la cintura?, ¿por qué las personas quedan bajitas? (Registro de observación, práctica I, mayo 5 del 2014).

A partir de la dimensión psicológica los estudiantes de grado 705 expresaron algunas inquietudes como:

¿Qué cambios emocionales se experimentan?, ¿por qué cambiamos la forma de pensar?, ¿por qué en la menstruación hay tantos cambios emocionales?, ¿en la vida de uno qué cambia más lo físico o lo emocional?, ¿por qué al hombre le gusta ver porno?, ¿por qué no podemos ser felices con nuestro cuerpo? (Registro de observación, práctica I, mayo 5 del 2014).

Desde la dimensión cultural, los educandos del grado 705 presentaron preguntas como:

\begin{abstract}
¿Por qué las personas se vuelven bisexuales?, ¿por qué la sociedad no nos acepta como somos?, ¿es bueno hacer ejercicio durante el crecimiento? (Registro de observación, práctica I, mayo 5 del 2014).
\end{abstract}

Por consiguiente, se inició una contextualización de la localidad novena de Fontibón (lugar donde se llevó a cabo la práctica pedagógica). La localidad está ubicada en la parte noroccidental de Bogotá. Al norte limita con la localidad de Engativá; al oriente con las localidades de Puente Aranda y Teusaquillo; al occidente con la ribera del río Bogotá y los municipios de Funza y Mosquera y al sur con la localidad de Kennedy. Fontibón tiene una extensión total de 3327 hectáreas (ha), de las cuales 329 están clasificadas como suelo protegido. La localidad no tiene suelo rural. Presenta una población total de 327933 habitantes (Alcaldía Mayor de Bogotá, 2009).

El Colegio Villemar el Carmen IED (donde se desarrolló la práctica pedagógica) está situado en el barrio Villemar, que se encuentra en la zona centro oriental de la localidad de Fontibón (Alcaldía Mayor de Bogotá, 2009). El colegio es una institución de índole distrital, mixto, con jornadas mañana y tarde, en el calendario $\mathrm{A}$, y admite estudiantes que pertenecen no solo al barrio Villemar, sino también a barrios aledaños.

En la zona confluyen espacios residenciales y de desarrollo industrial. El colegio cuenta con tres sedes: la sede A, situada en el barrio Villemar, brinda educación básica secundaria y media; la sede B, ubicada en el barrio Modelia; y la sede $C$, también localizada en el barrio Villemar, que ofrecen educación básica primaria. En todas las sedes, trabaja un personal mixto. Además, es una de las pocas instituciones del Distrito Capital y de la localidad que trabaja con el proyecto de inclusión de estudiantes con discapacidad cognitiva.

El manual de convivencia del Colegio Villemar el Carmen IED proclama en el proyecto educativo institucional (PEI): "Villemaristas líderes en comunicación, convivencia y participación"; a su vez, plantea como misión: "Formar jóvenes en competencias, habilidades y saberes comunicativos y de convivencia democrática para contribuir al éxito en su proyecto de vida y en la transformación de su entorno, incluyendo estudiantes con necesidades cognitivas especiales", y como visión: "En el año 2017, el Colegio Villemar el Carmen IED tendrá consolidados sus procesos pedagógicos y de gestión para ofrecer a la comunidad, a partir del desarrollo de habilidades comunicativas y de convivencia, ciudadanos autónomos, propositivos y éticos".

Esta investigación se adelantó en la sede A del Colegio Villemar el Carmen IED, localizada en la calle 20 D \# 96 G-51. Su planta física es relativamente nueva, está constituida por tres pisos y un patio, fue reestructurada en el año 2007. En cuanto a los recursos que posee, cuenta con dos salas de informática, un laboratorio de física y uno de química, un CRI (aula de idiomas), un aula múltiple y aulas inclusivas y exclusivas. Adicionalmente, la sede se beneficia de servicios como biblioteca, comedor escolar y almacén.

El grado con el cual se trabajó fue 705 de la jornada mañana, conformado inicialmente por 32 estudiantes, de los cuales dos presentaban necesidades cognitivas especiales. Cabe aclarar que al transcurrir la práctica se retiraron dos estudiantes. Los educandos participantes comprenden edades entre los 11 y 15 años y pertenecen a los estratos 2,3 y 4 .

Al realizar la contextualización de los aspectos de educación en sexualidad que se trabajan en el colegio anteriormente mencionado, en su manual de convivencia no se hace una referencia clara de la temática. La persona que se encarga de los proyectos de educación en sexualidad en 
la institución educativa es la orientadora, en este caso de la jornada mañana, que muy amablemente proporcionó algunos testimonios:

Los docentes del Colegio Villemar el Carmen IED, sede $A$, jornada mañana, implementan el proyecto de educación sexual en las distintas áreas a todo momento, cuando los profesores saludan a sus estudiantes y les dan la mano, se está presentado la sexualidad, la sexualidad se vive y se manifiesta de manera personal y en las relaciones con los/as demás.

En el área de biología, se hace un mayor énfasis en el proyecto de educación sexual, ya que los profesores les hablan a los estudiantes sobre el tema de la sexualidad a profundidad.

Los docentes en la institución buscan que las chicas se valoren a sí mismas y los muchachos asuman una actitud responsable frente a la sexualidad. (Entrevista a la orientadora Mariela Ramírez, 2 de abril de 2014).

Además, la orientadora resalta:

El proyecto de educación sexual promovido por la orientación, es básicamente talleres que se elaboran en conjunto con la Secretaría Distrital de Integración Social, la Secretaría de Educación Distrital y el Hospital de Fontibón, que tiene como objetivo que las estudiantes se valoren, a la vez los talleres buscan que se asuma la sexualidad con responsabilidad por parte de los chicos y chicas. Dichos talleres se llevan cabo todos los años.

El año pasado en el Colegio Villemar el Carmen IED, en la jornada mañana, se presentó tan solo un embarazo, pero este año hay cuatro embarazos registrados, situación que desmotiva un poco, pero el propósito es seguir luchando para que no se presenten estos casos en las jóvenes. De este modo, los logros que se han obtenido con el proyecto de educación sexual han sido la disminución de embarazos en la institución.

El año pasado se tuvo como invitado en el Colegio Villemar el Carmen IED al grupo teatral de la Doctora Clown que realizó una representación en torno a la educación sexual, además se trabajó fuertemente el tema con los estudiantes en su proyecto de vida.

Este año se va a implementar en el Colegio el programa ¿Bebé?, ¡Piénsalo bien!, que es liderado por la Alcaldía de la localidad de Fontibón junto al Hospital de Fontibón. Este proyecto se está desarrollando desde el año 2009 en la localidad, pero el barrio Villemar fue seleccionado como el último donde se desarrollará. (Entrevista a la orientadora Mariela Ramírez, 2 de abril de 2014).

No cabe duda que tanto las obras de teatro como el programa ¿Bebé?, ¡Piénsalo bien! son buenas estrategias para abordar el tema del cuerpo con los estudiantes, pero una educación integral en torno a la sexualidad debería tener más en cuenta las problemáticas que se les presentan día a día a los estudiantes en relación con dicho tema e incluso sus intereses e inquietudes, partiendo de ahí, el proceso de enseñanza puede ser más significativo para ellos.

Por último, la orientadora afirmó:

El proyecto de educación sexual lo hemos centrado hacia que los y las estudiantes se valoren, se respeten, se cuiden, reconozcan sus derechos sexuales, exploren otras dimensiones como la emocional, la social y la cultural, que primero tengan en mente su proyecto de vida, cómo van a realizar ese proyecto de vida, y luego sí piensen en sus hijos. Todos los profesores han colaborado y todos los estudiantes. (Entrevista a la orientadora Mariela Ramírez, 2 de mayo de 2014).

En los testimonios posteriores, se observa que la orientadora amplía su punto de vista sobre el proyecto de educación sexual que se desarrolla en el colegio y asegura que está tiene un enfoque integral, a través del cual los y las estudiantes se valoran, se respetan, se cuidan, reconocen sus derechos sexuales y piensan en su proyecto de vida. La presente investigación debe fortalecer el enfoque integral sobre sexualidad que se está llevando a cabo en el colegio, a través de un eje central como lo es el cuerpo, con el sentido de mejorar la calidad de vida de la comunidad a nivel local.

Cabe aclarar en este punto que esta investigación se concibió a partir de un paradigma cualitativo-interpretativo, entendido, según Ramírez, Arcila, Buriticá y Castrillón, como un paradigma que "se preocupa por el contexto de los acontecimientos, y centra su indagación en aquellos espacios en que los sujetos se implican e interesan, evalúan y experimentan directamente" (2004, p. 53).

Así, al identificar las concepciones de los estudiantes sobre el cuerpo y la sexualidad y establecer las relaciones de estas con los constructos teóricos, se necesita de la interpretación de tales relaciones para así describirlas y con ello llegar a decir si tales concepciones intervienen en el reconocimiento del cuerpo por parte de los estudiantes de séptimo del Colegio Villemar el Carmen IED, pues se evidenciaron a partir de sus formas de pensar y de actuar. 
Para lograr tal interpretación de la realidad, se empleó en la investigación una técnica denominada observación participante y un instrumento conocido como registro de observación, concebidos como base fundamental al instante de recopilar la información, ya que posibilitaron su sistematización e interpretación desde un objetivo determinado, con lo cual se consiguió una aproximación a la comprensión de la problemática planteada.

Cabe recordar que la observación participante es una técnica de recolección, en la que el observador tiene participación con la comunidad, participación que día tras día se llevó a cabo en el contexto escolar (Colegio Villemar el Carmen IED) y en algunas ocasiones fuera de este (en el barrio en general), desde las relaciones maestro-estudiante.

La información conseguida fue narrada periódicamente a través de los registros de observación, desde las experiencias vividas en la institución, las cuales contribuyeron al desarrollo de la investigación a partir de la realidad y adicionalmente a través de la plática constante con los educandos de grado 705 y la maestra titular del área de biología, que fueron complejizando el análisis de la investigación. El registro visual, es decir, las fotografías, permitieron recoger, a través de un documento visual, los momentos principales para la investigación que le dieron mayor sustento a la misma.

Por último, se utilizaron matrices de contingencia para sistematizar y facilitar el análisis de los resultados obtenidos. Sumado a lo anterior, se llevaron a cabo diversos talleres en el transcurso de la práctica pedagógica, que favorecieron el desarrollo de la investigación, a continuación se hace un paneo de aquellos que se realizaron en la práctica II:

- Taller 1 sobre las diferencias anatómicas, fisiológicas, psicológicas y culturales entre los sexos, con el objetivo de propiciar en las y los estudiantes el conocimiento del cuerpo, a través de la identificación de las características anatómicas, fisiológicas, psicológicas y culturales entre los sexos.

- Taller 2 sobre la sexualidad humana, con el objetivo de promover la reflexión de las y los estudiantes frente a la sexualidad como cualidad única del ser humano, íntimamente ligada al conocimiento del cuerpo y atravesada por las dimensiones biológica, psicológica y cultural.

- Taller 3 sobre el ciclo menstrual, las creencias y prácticas culturales que se tienen en torno a este, con el objetivo de lograr que las y los estudiantes comprendan el ciclo menstrual como un periodo natural en el cuerpo de la mujer, a partir de creencias y prácticas de diferentes partes del mundo.

- Taller 4 sobre la fecundación y el embarazo desde la dimensión biológica, psicológica y cultural, con el objetivo de conseguir que las y los estudiantes comprendan el proceso de fecundación y embarazo que ocurre en el cuerpo de la mujer, a partir de la dimensión biológica, psicológica y cultural así como desde la perspectiva de género.

- Taller 5 sobre los métodos anticonceptivos y las infecciones de transmisión sexual desde la dimensión biológica, psicológica y cultural, con el objetivo de reconocer las percepciones de las y los estudiantes sobre los métodos anticonceptivos y las infecciones de transmisión sexual (ITS) desde las diferentes dimensiones que atañen a la sexualidad.

Cada uno de los anteriores talleres fue planeado y elaborado de acuerdo a las edades y el contexto en el que se encontró el grupo de estudiantes. Cabe resaltar que las diversas metodologías utilizadas fueron invención de la autora de esta investigación.

\section{Resultados y discusión}

\section{Reconocimiento de sí mismo y del otro a partir del cuerpo}

Respecto a las concepciones sobre el cuerpo de los estudiantes, se encontró que estos reconocen que la imagen que ellos pueden observar de sí mismos es el exterior de su cuerpo y sobre él inminentemente cada sujeto hace una serie de valoraciones en relación a su físico y a los cambios que ha evidenciado en su propio cuerpo, a partir del reconocimiento que todo el tiempo, como seres humanos, hacemos acerca de nuestros cuerpos y de los cuerpos de los demás.

Por ende, desde el campo biológico, algunos estudiantes de grado 705 presentaron los siguientes testimonios en relación con su propio cuerpo y el cuerpo de uno de sus compañeros, los cuales evidencian una serie de valoraciones respecto a las características físicas de sí mismos y de los demás:

Lo que me gusta de mí son mis ojos, mi pelo y mis manos. Mis cambios fueron el peinado y me salieron granos en la cara. Crecí rápidamente en altura. Se me engrosó la voz. - Me gusta tu cabello y tus ojos- [opinión del compañero(a) de pupitre]. ( $E_{1}$ y $E_{2}$, taller 1 , 
"sobre los cambios físicos de las niñas y los niños al entrar a la pubertad”, práctica I, abril 21 del 2014).

Me gusta todo de mí. Me crecieron los pelos genitales. Me crecieron los pelos de las piernas y los brazos, he crecido. Se me ha engrosado un poquito la voz. $-\mathrm{Me}$ gusta tu cabello- [opinión del compañero(a) de pupitre]. ( $E_{3}$ y $E_{4}$, taller 1 , "sobre los cambios físicos de las niñas y los niños al entrar a la pubertad", práctica I, abril 21 del 2014).

Me gusta mi cabello, me gustan mis ojos, me gustan mis manos y me gustan mis pies. Me ha salido vello en los genitales. No he crecido. - Me gusta el color de tu piel y me gusta el color de tu cabello- [opinión del compañero(a) de pupitre]. ( $E_{5}$ y $E_{6}$, taller 1 , "sobre los cambios físicos de las niñas y los niños al entrar a la pubertad", práctica I, abril 21 del 2014).

De acuerdo con lo anterior, las valoraciones que presentaron los estudiantes de grado 705 en relación a sus cuerpos y a los de los demás no vienen implantadas en sus organismos, son concepciones que fueron aprendiendo en la medida que se fueron integrando en la sociedad. Mientras crecían comenzaron a fijarse en cosas que antes no veían. Empezaron a determinar qué características físicas de su cuerpo son lindas y cuáles no, qué cambios han presentado corporalmente y cuáles no, lo mismo hacen con el cuerpo de las personas que los rodean.

A la vez, desde el campo biológico, la mayoría de estudiantes de grado 705 afirman no saber que los constituyentes del sexo son los sistemas reproductores (genitales internos y externos), las características sexuales secundarias, el componente hormonal y la composición cromosómica, entendido el sexo como las diferencias biológicas que se evidencian en los cuerpos de hombres y mujeres, tanto interna como externamente. Los estudiantes de grado 705 manifiestan que las diferencias anatómicas y fisiológicas entre hombres y mujeres se establecen a partir de algunos órganos externos y ciertas características sexuales secundarias. Lo anterior se puede evidenciar en los testimonios que dieron algunos estudiantes:

El contenido y desarrollo del tema diferencias anatómicas y fisiológicas entre los sexos, sí le aportó a mi vida personal, porque me interesó entender las diferencias entre hombres y mujeres. Yo no sabía que los hombres y las mujeres tenían diferente hormona sexual, pues el hombre tiene la hormona testosterona y la mujer la hormona estrógeno. (E $E_{11}$, taller 1, "sobre las diferencias anatómicas, fisiológicas, psicológicas y culturales entre los sexos”, práctica II, julio 30 y agosto 4 del 2014).
El contenido y desarrollo del tema diferencias anatómicas y fisiológicas entre los sexos, sí le aportó a mi vida, porque pude saber la diferencia entre el hombre y la mujer y pude descubrir las diferencias entre nuestros órganos. Yo no sabía que los cromosomas, en el hombre eran XY y en la mujer XX. (E12, taller 1, "sobre las diferencias anatómicas, fisiológicas, psicológicas y culturales entre los sexos", práctica II, julio 30 y agosto 4 del 2014).

El contenido y desarrollo del tema diferencias anatómicas y fisiológicas entre los sexos, sí le aportó a mi vida, porque pude conocer y diferenciar cada uno de nuestros órganos internos y externos. Fue importante entender que tanto hombre como mujer tienen partes íntimas diferentes. ( $E_{13}$, taller 1, "sobre las diferencias anatómicas, fisiológicas, psicológicas y culturales entre los sexos", práctica II, julio 30 y agosto 4 del 2014).

Teniendo en cuenta lo previo, se puede afirmar que el reconocimiento de las diferencias corporales tanto internas como externas entre hombres y mujeres se configura desde las diversas etapas de la vida de cada sujeto, de esta forma, cada sujeto desarrolla un sentido personal de sí mismo y de su propio cuerpo en función de sus experiencias, de su historia, de sus características y de sus percepciones, así como en función de sus interacciones y de los valores y normas que rigen su cultura.

Cabe resaltar que los estudiantes de grado 705 reconocen que sus cuerpos no solo están constituidos por un campo biológico, sino también por un campo psicológico, pues es a través de sus cuerpos que expresan emociones, sentimientos y pensamientos, exploran recuerdos trascendentales para su vida presente y futura, lo que permite el reconocimiento de sí mismos y por tanto de los otros. Algunos estudiantes expresaron ciertas emociones, sentimientos, pensamientos y recuerdos, que experimentaron en su infancia y otros que son más recientes, estos se pueden apreciar a través de los siguientes testimonios:

Cuando tenía 5 o 6 años, vivía con mis abuelos porque mi papá nos abandonó y mi mamá estuvo con nosotros. Eso me hizo sentir un poquito mal. Ahorita en la actualidad, mi papá nos buscó, para ese entonces yo ya le tenía mucho rencor. (E16, taller 2, "sobre los cambios psicológicos de las niñas y los niños al entrar a la pubertad", práctica I, mayo 5 y 14 del 2014).

Yo recordé cuando mi mamita me consentía, cuando yo jugaba con mi primo, cuando mi papito me llevaba al parque. Tengo una emoción y alegría por tener una familia tan unida. ( $E_{18}$, taller 2, "sobre los cambios psi- 
cológicos de las niñas y los niños al entrar a la pubertad", práctica I, mayo 5 y 14 del 2014).

Sentí un sentimiento de felicidad al recordar que estaba con mis primos, pero a la vez a los seis años mis sentimientos eran tristes por lo que mi padre se había ido con otra persona y nos dejó. También me di cuenta que había cambiado de los 6 años hasta hoy en mi forma de ser, que he crecido, que me habían cambiado muchos rasgos. (E20, taller 2, "sobre los cambios psicológicos de las niñas y los niños al entrar a la pubertad", práctica I, mayo 5 y 14 del 2014).

Partiendo de lo preliminar, se puede decir que la historia personal de cada uno de los estudiantes de grado 705 y las vivencias que cada uno tuvo o ha tenido están enmarcadas por sus emociones, sus sentimientos, sus pensamientos y sus recuerdos, los cuales pasan a ser parte de su cuerpo y les permite reconocerse a sí mismos y reconocer del mismo modo a los otros.

Por último, desde el campo cultural los estudiantes de grado 705 expresan que los mensajes que reciben socioculturalmente acerca de qué ropa les queda bien, qué gestos gustan, qué movimientos llaman la atención, qué pueden hacer y qué no, y qué deben hacer con su cuerpo, hacen que ellos como hombres y mujeres actúen y se expresen de formas diferentes a partir de su cuerpo. Por lo tanto, algunos estudiantes nos dan a conocer cómo se visten ahora y cómo se vestían más pequeños, qué hacen ahora y qué hacían más chicos, sobre qué hablan con los(as) amigos(as) y qué juguetes tenían cuando estaban más pequeños, a través de sus testimonios:

Me gusta vestir bien. En la actualidad me gusta y recuerdo cuando salgo al parque con mis hermanos y primos y jugamos fútbol. (E21, taller 2, "sobre los cambios psicológicos de las niñas y los niños al entrar a la pubertad", práctica I, mayo 5 y 14 del 2014).

Yo me visto con pantalones blancos, negros y rojos, estos colores son los que más me gustan. De camisas uso negras o rojas, zapatos negros o rojos, de esta forma es la que más me gusta vestirme. Cuando era un bebé me vestían con overoles y me cuidaba mi mamá. Cuando tenía 5 a 6 años yo jugaba con mis vecinos yermis, ponchados, escondidas, stop y fútbol. Lo que más me gusta hacer es jugar fútbol. Yo hablo con mis amigos sobre qué vamos a hacer, que cómo están, entre otras cosas. (E22, taller 2, "sobre los cambios psicológicos de las niñas y los niños al entrar a la pubertad”, práctica I, mayo 5 y 14 del 2014).
Yo me vestía con pantaloneta, camisa, zapatos. Mi primer juguete fue una mula con carros pequeños. ( $E_{23}$, taller 2, "sobre los cambios psicológicos de las niñas y los niños al entrar a la pubertad”, práctica I, mayo 5 y 14 del 2014).

Yo jugaba con mis muñecas cuando era pequeña. ( $E_{28}$, taller 2, "sobre los cambios psicológicos de las niñas y los niños al entrar a la pubertad", práctica I, mayo 5 y 14 del 2014).

Respecto a lo anterior, se puede afirmar que en la medida que los estudiantes de grado 705 fueron aprendiendo socioculturalmente nociones sobre su cuerpo en las diferentes etapas de su vida, su cuerpo dejó de ser solo un organismo y se convirtió en un organismo valorado por cada uno de ellos y por los demás, atravesado por las dimensiones biológica, psicológica y cultural, que construyeron la imagen que cada uno tiene de su propio cuerpo y del cuerpo de los demás. Hay que destacar que dicha idea se construyó en el intercambio constante con los otros.

\section{La sexualidad como un entramado de dimensiones a través de las cuales se explora el cuerpo}

Frente a las concepciones sobre sexualidad y el cuerpo de los estudiantes de grado 705, jornada mañana del Colegio Villemar el Carmen IED, se halló que estos conciben la sexualidad como una cualidad única del ser humano, que está presente en todas las etapas de su vida y que está constituida por múltiples dimensiones como la biológica, la psicológica y la cultural. Por ende, reconocen que a través de su cuerpo exploran su sexualidad, desde la manera en que se ven a sí mismos y a los otros, que pueden manifestarse y relacionarse con los demás, hasta el modo de sentir y de comunicarse afectiva y socialmente.

Por tal motivo, los estudiantes de grado 705 presentaron los siguientes testimonios en relación a lo que entienden por sexualidad de una forma integral y la manera como esta se experimenta a partir de su cuerpo:

Para vivir la sexualidad en una relación sentimental con una persona se necesita amor y sentimientos, para poder llegar a sentir placer y pasión por una persona. $\left(E_{1}, E_{2}, E_{3}, E_{4}, E_{5}, E_{6}, E_{7}\right.$; Registro de observación 9, práctica II, agosto 20 del 2014).

A través de la sexualidad se experimenta y se expresa el amor, el placer, la excitación, la pasión, el cariño, la confianza, la amistad y la felicidad. (E $\mathrm{E}_{8}, \mathrm{E}_{9}, \mathrm{E}_{10}, \mathrm{E}_{11}$, 
$E_{12}, E_{13}, E_{14}, E_{15}$; Registro de observación 9, práctica II, agosto 20 del 2014).

La sexualidad es el placer de expresarse normalmente, amarse y darse cariño, tener deseos de pasión con amor y tener mucho romance. ( $E_{16}, E_{17}, E_{18}, E_{19}, E_{20}$, $E_{21}, E_{22}, E_{22}, E_{24}$; Registro de observación 9, práctica II, agosto 20 del 2014).

La sexualidad es una acción que se da con respeto y amor, es realizada por dos individuos, depende de la atracción, es algo normal en parejas y así expresan nuevos sentimientos. ( $E_{25}, E_{26}, E_{27}, E_{28}, E_{29}, E_{30}, E_{31}$, $E_{32}$; Registro de observación 9, práctica II, agosto 20 del 2014).

Según lo anterior, se puede decir que los estudiantes de grado 705 reconocen y manifiestan en cada una de sus posturas frente a la sexualidad que es un entramado de manifestaciones y expresiones afectivas, biológicas, psicológicas, socioculturales y éticas, que nos identifica y caracteriza como sujetos únicos. Además, establecieron que hablar de sexualidad es pensar en placer y responsabilidad, es el modo en que cada uno experimenta su cuerpo en las diferentes etapas de su vida.

Los estudiantes de grado 705 expresan que lo que tanto hombres como mujeres piensan, hablan, sienten y hacen respecto a la sexualidad, está determinado por el contexto sociocultural en el que se desenvuelven, pues este es el que brinda las pautas sobre qué deben pensar, qué deben decir, cómo se deben expresar y cómo deben actuar en la sociedad los sujetos, dependiendo si son hombres o si son mujeres.

De esta manera, algunos educandos expusieron a través del dibujo de una mujer y de un hombre, los siguientes testimonios en relación con lo que ellos consideran que piensan, hablan, sienten y hacen hombres y mujeres sobre la sexualidad:

1. Cabeza: Lo que piensan los hombres es tener una vida amorosa y tener hijos. Lo que piensan las mujeres es tener novio, son importantes para ellas los sentimientos y tener relaciones de amor. [...] 2. Boca: Los hombres son sinceros con las palabras que expresan. Las mujeres hablan cosas lindas de su novio. [...] 3. Corazón: Los hombres sienten que deben ser sinceros con su pareja, que deben amarla y tener miedo que algo le pase. Las mujeres sienten que deben expresar sus sentimientos hacia el novio. [...] 4. Manos: Los hombres abrazan, tocan y acarician. Las mujeres le dan caricias al novio, le dan abrazos y dan cariño. ( $E_{1}, E_{2}, E_{3}$, $E_{4}, E_{5}, E_{6}, E_{7}, E_{8}, E_{9}$; Registro de observación 12, práctica II, septiembre 1 del 2014).
1. Cabeza: Lo que piensan los hombres es protegerse antes y durante las relaciones sexuales. Lo que piensan las mujeres es sentir el placer sexual pero previniendo un embarazo. [...] 2. Boca: Los hombres siempre están hablando sobre el tema de la sexualidad. Las mujeres son más reservadas en el tema de la sexualidad, pero igual les gusta conocer más a fondo el tema. [...] 3. Manos: Los hombres le dan detalles a las mujeres para conquistarlas. Las mujeres demuestran afecto mediante abrazos, besos y caricias. ( $E_{10}, E_{11}, E_{12}, E_{13}$, $\mathrm{E}_{14}, \mathrm{E}_{15}, \mathrm{E}_{16}, \mathrm{E}_{17}$; Registro de observación 12, práctica II, septiembre 1 del 2014).

Teniendo en cuenta lo precedente, se puede afirmar que los estudiantes de grado 705 reconocen y manifiestan, a partir de lo que han escuchado socialmente y de sus vivencias, que tanto sus formas de pensar, expresarse, sentir y actuar frente a la sexualidad y, por consiguiente, la manera de experimentar su sexualidad a través de su cuerpo, están mediadas por las pautas que sus padres desde pequeños les enseñaron y asimismo por las que adquirieron en el ámbito sociocultural.

\section{Reconocimiento del cuerpo de la mujer a partir del ciclo menstrual}

Respecto a las concepciones sobre el cuerpo de la mujer a partir del ciclo menstrual de los estudiantes, se encontró que estos consideran que el ciclo menstrual es un periodo normal y natural por el que atraviesa el cuerpo de la mujer, que desde un punto de vista biológico consiste en la maduración de los óvulos. Pero dicho proceso, a su vez, está configurado por factores psicológicos, ya que durante tal periodo la mujer experimenta en su cuerpo una serie de cambios emocionales influenciados por las hormonas conocidas como estrógenos. Además, los educandos reconocen que en torno al ciclo menstrual se tejen varias creencias y prácticas de diferentes culturas del mundo y del país que permiten reconocer el cuerpo de la mujer a partir de este ciclo.

De este modo, algunos estudiantes presentaron los siguientes testimonios en relación con el reconocimiento del cuerpo de la mujer desde la comprensión del ciclo menstrual:

El contenido y desarrollo del tema el ciclo menstrual, sí le aportó a mi vida personal, porque aprendí que el ciclo menstrual en las mujeres es normal y que no hay nada de que asustarse, además es cuando la mujer empieza a crecer. Me parecieron importantes las siguientes ideas: el ciclo menstrual es algo normal en toda mujer y cuando pasa esto debemos visitar al

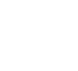

(1)


doctor para que no haya ningún problema en nuestro crecimiento. ( $E_{1}$; Registro de observación 20 , práctica II, octubre 1 del 2014).

El contenido y desarrollo del tema el ciclo menstrual, sí le aportó a mi vida personal, porque me ayudó a conocer mejor el cuerpo de la mujer. (E2; Registro de observación 20, práctica II, octubre 1 del 2014).

El contenido y desarrollo del tema el ciclo menstrual, sí le aportó a mi vida personal, porque aunque solo las mujeres tengan la menstruación, sirve para la vida personal de una pareja, por ejemplo cuando la mujer tiene la menstruación y tiene relaciones sexuales, la higiene sirve para prevenir infecciones. Me pareció importante saber el tiempo en el que la mujer puede quedar embarazada, para evitar embarazos no deseados. (E3; Registro de observación 20, práctica II, octubre 1 del 2014).

El contenido y desarrollo del tema el ciclo menstrual, sí le aportó a mi vida personal, porque pude entender a las mujeres y saber un poco más sobre ellas. Me pareció importante aprender más sobre el tema del ciclo menstrual y saber más cosas nuevas. (E⿰氵 $E_{9}$ Registro de observación 20, práctica II, octubre 1 del 2014).

Pensamos que las creencias de los wayú no son muy válidas, porque cuando una mujer se desarroIla no tiene que ser obligada a casarse. Conocemos la siguiente creencia: cuando a una mujer le llega el periodo menstrual no puede salir a la calle porque la gente se da cuenta. ( $E_{11}, E_{12}, E_{13}, E_{14}, E_{15}$; Registro de observación 19, práctica II, septiembre 29 del 2014).

De la práctica de las tribus indígenas, del Brasil y de la Guayana Francesa, en la cual maltrataban a las adolescentes hasta el desmayo cuando menstruaban en abundancia, pensamos que eran muy crueles con las jóvenes, ya que la menstruación es algo normal y no es nada del otro mundo. Conocemos una creencia y práctica de la tribu africana: ellos creían que la menstruación era un pecado de la mujer porque pensaban que expulsaban parte de su ser. Así que, al ser la mujer adolescente, le cortaban las trompas de Falopio para que no pudiera menstruar ni tener hijos. ( $E_{16}, E_{17}, E_{18}$, $E_{19}, E_{20}$; Registro de observación 19, práctica II, septiembre 29 del 2014).

La creencia que teníamos sobre el ciclo menstrual era: entre la comunidad indígena hindú de los manu, se creía que un hombre que tuviera relaciones sexuales con una mujer con la menstruación perdía su fuerza física, su energía de vivir, su sabiduría y su cordura. De esa creencia y práctica, pensamos que es una narra- ción que no es verdadera. Conocemos las siguientes creencias: cuando la mujer tiene la menstruación, al tener relaciones sexuales puede sangrar y si no hay una buena higiene, puede haber una infección en el pene del hombre. ( $E_{21}, E_{22}, E_{23}$, E24; Registro de observación 20, práctica II, octubre 1 del 2014).

Partiendo de lo anterior, se puede decir que, a través de la explicación que se llevó a cabo sobre el ciclo menstrual, los estudiantes hombres del grado 705 lograron conocer los cambios biológicos y psicológicos que ocurren en el cuerpo de la mujer a raíz de dicho ciclo y, por su parte, las mujeres lograron reconocer su propio cuerpo y empoderase de él. A su vez, tanto hombres como mujeres establecieron que conociendo el ciclo menstrual se puede entender en qué días hay riesgos para que la mujer quede en embarazo, por lo tanto, aseguraron que sabiendo los días fértiles de la mujer se pueden emplear métodos anticonceptivos para evitar los embarazos no deseados. Otros manifestaron que fue esencial entender que, si se tienen relaciones sexuales durante la menstruación, es muy importante realizar una higiene adecuada en los genitales masculinos y femeninos después del acto para evitar las infecciones de transmisión sexual. Por último, algunos educandos reconocieron que ahora sí comprenden los cambios de las mujeres en su forma de actuar, ya que estos se deben a las hormonas estrógenos. Igualmente, se evidenció que ellos fueron críticos a la hora de evaluar algunas prácticas y creencias que ciertas culturas tienen alrededor del ciclo menstrual y que por lo tanto inciden en la exploración del cuerpo, también expresaron las creencias que conocían sobre el ciclo menstrual, lo que posibilitó aclarar la veracidad de las mismas en el aula de forma colectiva.

\section{Reconocimiento del cuerpo de la mujer desde el proceso de fecundación y embarazo}

Frente a las concepciones sobre la fecundación y el embarazo de los estudiantes de grado 705, jornada mañana, del Colegio Villemar el Carmen IED, se halló que estos conciben la fecundación como un proceso netamente biológico que ocurre en el cuerpo de la mujer, en el que el espermatozoide del hombre se une con el óvulo y logra que la mujer quede en embarazo. Por su parte, el embarazo lo conciben como un proceso biológico que experimenta la mujer en su cuerpo y está estrechamente ligado con factores psicológicos y culturales, lo entienden como el desarrollo del bebé en el útero de su madre, el cual surge de la unión del espermatozoide del hombre con el óvulo de la mujer. 
Por tal motivo, algunos estudiantes expresaron los siguientes testimonios con relación al proceso de fecundación y embarazo, experimentado en el cuerpo de la mujer, desde el campo biológico:

Nosotros pensamos que la fecundación es cuando el semen del hombre entra al cuerpo de la mujer y queda en embarazo. ( $E_{1}, E_{2}$; Registro de observación 21, práctica II, octubre 15 del 2014).

Nosotros creemos que el embarazo se divide en nueve etapas, porque dura el embarazo nueve meses. ( $E_{3}$, E4; Registro de observación 21, práctica II, octubre 15 del 2014).

Nosotros pensamos que el embarazo es cuando el hombre y la mujer tienen relaciones sexuales y el hombre crea espermatozoides llegando al óvulo de la mujer y esta queda en embarazo. ( $E_{5}, E_{6}$; Registro de observación 21, práctica II, octubre 15 del 2014).

Nosotros creemos que las etapas del embarazo se dividen en tres grupos, cada grupo dura tres meses. ( $E_{11}$, $E_{12}$; Registro de observación 21, práctica II, octubre 15 del 2014).

Nosotros creemos que los síntomas de una mujer embarazada pueden ser mareo, cólicos, vomito, ansias, dolores de cabeza, y dolor de espalda. ( $\mathrm{E}_{15}, \mathrm{E}_{16}$; Registro de observación 21, práctica II, octubre 15 del 2014).

De acuerdo con lo anterior, se puede señalar que los estudiantes del grado 705 manifiestan, a partir de lo que han escuchado y evidenciado, entender que el proceso de fecundación es la capacidad de embarazarse de la mujer mediante la unión de un óvulo y un espermatozoide en una de las trompas de Falopio. Asimismo, los estudiantes lograron determinar que el embarazo dura nueve meses, se divide en tres trimestres y la mujer puede experimentar síntomas a través de su cuerpo como mareo, cólicos, vómito, ansias, dolores de cabeza y dolor de espalda.

De igual manera, desde el campo psicológico y cultural, respecto al embarazo, los estudiantes expresan que la condición de la mujer, en muchas ocasiones, puede depender en parte del hecho de tener hijos. Sin embargo, en donde las mujeres están logrando oportunidades en otras áreas de la vida, ellas pueden sentir menor presión para tenerlos. Además, los educandos manifiestan que día a día los hombres están tomando un rol más activo frente al embarazo, lo que evidencia la responsabilidad tanto del padre como de la madre en dicho proceso.
Lo anterior consta en los testimonios que dieron algunos estudiantes respecto al embarazo, como un proceso atravesado por factores psicológicos y culturales:

Pensamos que el embarazo es responsabilidad tanto del padre como de la madre, aunque hay padres que abandonan a sus hijos y no quieren responder por ellos. Finalmente, tanto el padre como la madre tuvieron la relación sexual y ambos quedaron embarazados. También hay responsabilidad de los padres de los jóvenes, pues como padres deben saber que si la chica tiene novio puede quedar embarazada. ( $\mathrm{E}_{6}, \mathrm{E}_{7}, \mathrm{E}_{8}, \mathrm{E}_{9}$; Registro de observación 23, práctica II, octubre 22 del 2014).

Pensamos que las mujeres adolescentes se embarazan a tan temprana edad porque quieren experimentar lo que se siente al tener relaciones sexuales y por no protegerse quedan embarazadas. Dicha situación se presenta a temprana edad, porque en la casa no están pendientes de sus hijos(as). También, influye que algunos hombres obligan a la chica a tener relaciones sexuales. A su vez, hay embarazos a temprana edad porque las niñas quieren conocer más niños, sentirse satisfechas y sentir placer sexual. Además, las chicas quedan embarazadas a temprana edad por influencias y presiones. ( $E_{10}, E_{11}, E_{12}, E_{13}$; Registro de observación 23 , práctica II, octubre 22 del 2014).

Pensamos que el amor es importante cuando se tiene un bebé porque un hijo le cambia la vida a sus padres, pues ellos deben proporcionarle a ese hijo amor y valores durante toda su vida, es una muestra de cuidado con ese nuevo ser y de responsabilidad. (E14, E15, $\mathrm{E}_{16}, \mathrm{E}_{17}$; Registro de observación 23, práctica II, octubre 22 del 2014).

Pensamos que las implicaciones que se presentan a nivel familiar a raíz de un embarazo son principalmente peleas con los padres, pues ellos esperan que los(as) hijos(as) estudien y se preparen, pero un embarazo impide que se siga estudiando, por eso, debemos ser conscientes que todo tiene que ser a su tiempo. En el caso que una chica como nosotras resulte embarazada debe recibir el apoyo y los consejos de los papás. ( $E_{18}, E_{19}, E_{20}, E_{21}$; Registro de observación 23, práctica II, octubre 22 del 2014).

Conforme con lo anterior, se puede decir que los estudiantes expresan desde lo que han escuchado y evidenciado que la mujer es la dueña de su cuerpo y por lo tanto la que decide sobre él, por ende, una mujer puede elegir si quiere tener hijos o no quiere tener hijos. Además, reconocen que algunas personas creen que el embarazo debe ocurrir solamente dentro de la relación aprobada socialmente del 
matrimonio, pero otros consideran que las y los niños pueden crecer felices y saludables, si sus padres les brindan el amor y los valores necesarios, sin importar la forma que tome su familia, aunque no en todos los casos se presenta la situación anterior, pues algunos padres no aceptan a sus hijos(as) y los(as) rechazan. Por otra parte, los educandos manifiestan que, según lo que han evidenciado cotidianamente, cada vez más los padres están presentes a lo largo de todo el embarazo, participando activamente en el cuidado de sus hijos o hijas, y haciendo honor a que tanto el padre como la madre deben responsabilizarse del embarazo. Finalmente, a partir de lo que han observado diariamente dichos estudiantes comprendieron que las jóvenes resultan embarazadas a tan temprana edad porque quieren experimentar lo que implica tener relaciones sexuales y por no protegerse quedan embarazadas, también sucede por influencias o presiones sociales o en su defecto del mismo novio; que llevan a que en el ámbito familiar se desaten conflictos, pues los padres de familia esperaban que sus hijos(as) estudiaran y se superaran, pero un embarazo no planeado trunca esos sueños, por eso, un embrazo es una decisión que se debe tomar a su debido tiempo.

\section{Autovaloración y bienestar del cuerpo desde el conocimiento de los métodos anticonceptivos y las ITS}

Respecto a las concepciones sobre los métodos anticonceptivos y las ITS como fuentes primarias de la autovaloración y bienestar del cuerpo, se encontró que los estudiantes de grado 705, jornada mañana, del Colegio Villemar el Carmen IED, consideran que las personas pueden experimentar a través de su cuerpo consecuencias positivas y negativas como resultado de su actividad sexual, en una dimensión biológica, psicológica y cultural. Según los educandos, los resultados positivos en torno al cuerpo incluyen desde el ámbito biológico, el placer, la intimidad y en las parejas heterosexuales el embarazo deseado, desde el ámbito psicológico incluye la estabilidad emocional y desde el ámbito cultural la acogida calurosa del embarazo por parte de la pareja y de la sociedad en general. En cuanto a las consecuencias negativas en torno al cuerpo incluyen desde el ámbito biológico, el daño físico, las infecciones de transmisión sexual, incluido el VIH y en las parejas heterosexuales el embarazo no planeado, desde el ámbito psicológico incluye el daño emocional y desde el ámbito cultural el rechazo por parte de la pareja y de la sociedad en general.

Por tal motivo, los estudiantes, en aras de la autovaloración y bienestar de su cuerpo a partir de las múltiples dimensiones que lo constituyen, desde el conocimiento de los métodos anticonceptivos y las ITS, expresaron los siguientes testimonios:

La mejor manera de combatir las ITS es utilizando el condón. ( $E_{1}, E_{2}, E_{3}, E_{4}, E_{5}$; Registro de observación 25, práctica II, octubre 29 del 2014).

El condón se pone en el pene evitando que el hombre o la mujer contraigan ITS. Los anticonceptivos son pastillas que utilizan las mujeres para evitar el embazo. ( $E_{6}$, $E_{7}, E_{8}, E_{9}, E_{10}$; Registro de observación No 25, práctica II, octubre 29 del 2014).

Las ITS si no se protegen en el coito, pueden transmitirse de una persona a otra, además el bebé puede nacer con ITS o malformaciones y problemas mentales. $\left(\mathrm{E}_{11}, \mathrm{E}_{12}, \mathrm{E}_{13}, \mathrm{E}_{14}, \mathrm{E}_{15}\right.$; Registro de observación 25, práctica II, octubre 29 del 2014).

Las ITS pueden transmitirse por no cuidarse, por medio de una relación sexual sin protección. ( $E_{16}, E_{17}, E_{18}, E_{19}$, $E_{20}$; Registro de observación 25, práctica II, octubre 29 del 2014).

A nosotros nos parece que no solo las trabajadoras sexuales, los homosexuales y las lesbianas adquieren las ITS. Todas las personas por no protegerse pueden adquirir las ITS, al no usar el condón, hay que tener mucho cuidado que el condón no se rompa. $\left(E_{21}, E_{22}\right.$, $E_{23}$, E24, E25; Registro de observación 25, práctica II, octubre 29 del 2014).

El condón es el método más eficiente para combatir las ITS y los embarazos, mientras que las pastillas que toman las mujeres solo previenen los embarazos. ( $E_{26}$, $E_{27}, E_{28}, E_{29}, E_{30}$; Registro de observación 25, práctica II, octubre 29 del 2014).

Partiendo de lo preliminar, se puede decir que los estudiantes reconocen y analizan la consigna en relación a que toda persona tiene el derecho de protegerse a sí misma contra las ITS y los embarazos no planeados. Hay varios métodos anticonceptivos para ello. Esto es aplicable tanto para parejas homosexuales como heterosexuales. Además, los educandos vislumbraron que el conocimiento de los métodos anticonceptivos no solo es importante para obtener un bienestar físico, en torno al cuerpo, sino además un bienestar psicológico y una aceptación incondicional por parte de la pareja así como de la sociedad en general. 


\section{Conclusiones}

A partir de esta experiencia investigativa, se puede concluir que la educación en sexualidad es vital en la escuela, porque parte del reconocimiento del sujeto, de su cuerpo, de sus sentimientos y emociones, así como de sus creencias adquiridas culturalmente, como base del quehacer pedagógico. Considera que el cuerpo trasciende lo biológico, pues contempla un entramado múltiple de factores como el psicológico y el cultural, de esta manera, el cuerpo es un territorio de experiencia y de expresión de nuestros sentimientos y emociones, además, es una fuente de sensaciones diferentes entre sí, pero todas estas son importantes en la construcción de nuestra subjetividad y de nuestra ciudadanía, en la medida que podamos entenderlas.

De esta manera, como resultado de la investigación llevada a cabo con los estudiantes de grado séptimo del Colegio Villemar el Carmen IED, es posible concluir que las valoraciones que presentaron dichos estudiantes en relación con sus cuerpos y los de los demás no vienen implantadas en sus organismos, son concepciones que fueron aprendiendo en la medida que se fueron integrando en la sociedad. En la medida que fueron creciendo, en ese momento, comenzaron a fijarse en cosas que antes no veían. Empezaron a determinar qué características físicas de su cuerpo son lindas y cuáles no, qué cambios han presentado corporalmente y cuáles no, lo mismo hacen con el cuerpo de las personas que los rodean.

A raíz de lo anterior, se puede deducir que el reconocimiento de las diferencias corporales tanto internas como externas por parte de los estudiantes de grado séptimo del Colegio Villemar el Carmen IED se ha configurado desde las diversas etapas de su vida, de esta forma, cada uno ha desarrollado un sentido de sí mismo y de su propio cuerpo en función de sus experiencias, de su historia, de sus características y de sus percepciones, así como en función de sus interacciones y de los valores y normas que rigen su cultura.

A su vez, se puede concluir que la historia personal de cada uno de los estudiantes, y las vivencias que cada uno tuvo o ha tenido, han estado enmarcadas por sus emociones, sus sentimientos, sus pensamientos y sus recuerdos, los cuales han pasado a ser parte de su cuerpo y les ha permitido reconocerse a sí mismos y reconocer del mismo modo a los otros.

Por otra parte, los estudiantes que hicieron parte de esta investigación permiten determinar que los mensajes que reciben socioculturalmente acerca de qué ropa les queda bien, qué gestos gustan, qué movimientos llaman la atención, qué pueden hacery qué no, y qué deben hacer con su cuerpo, hacen que ellos como hombres y mujeres actúen y se expresen de formas diferentes a partir de su cuerpo.
Además, a partir de esta investigación se puede deducir que los estudiantes de grado séptimo del Colegio Villemar el Carmen IED consideran que el ciclo menstrual es un periodo normal y natural por el que atraviesa el cuerpo de la mujer, que desde un punto de vista biológico consiste en la maduración de los óvulos. Pero dicho proceso, a la par, está configurado por factores psicológicos, ya que durante tal periodo la mujer experimenta en su cuerpo una serie de cambios emocionales que están influenciados por las hormonas conocidas como estrógenos. Igualmente, los educandos reconocen que en torno al ciclo menstrual, se tejen varias creencias y prácticas de diferentes culturas del mundo y del país, que permiten reconocer el cuerpo de la mujer a partir de este ciclo.

Se puede concluir que los estudiantes anteriormente mencionados conciben la fecundación como un proceso netamente biológico que ocurre en el cuerpo de la mujer, en el que el espermatozoide del hombre se une con el óvulo y logra que la mujer quede en embarazo. Por su parte, el embarazo lo conciben como un proceso biológico que experimenta la mujer en su cuerpo y está estrechamente ligado con factores psicológicos y culturales, por eso lo entienden como el desarrollo del bebé en el útero de su madre, el cual surge de la unión del espermatozoide del hombre con el óvulo de la mujer.

Finalmente, se puede determinar que los estudiantes de grado séptimo del Colegio Villemar el Carmen IED consideran que las personas pueden experimentar a través de su cuerpo consecuencias tanto positivas como negativas que resultan de su actividad sexual, en una dimensión biológica, psicológica y cultural.

\section{Agradecimientos}

En primer lugar, agradezco a la Universidad Pedagógica Nacional de Colombia, sede Bogotá, como institución patrocinante de la presente investigación, al Departamento de Biología y a la línea de investigación del mismo departamento "Configuración de los conocimientos acerca de lo vivo y de la vida en contextos culturalmente diversos", por su apoyo y colaboración. Por último, agradezco al Colegio Villemar el Carmen IED; a su rector, Pablo Alejandro Salazar; a la maestra de biología, Doris Román; a la orientadora Mariela Ramírez; a los demás directivos de la institución y maestros de la jornada mañana, por permitir el desarrollo de la presente investigación, así como por el apoyo y la colaboración prestada. A su vez, agradezco y resalto la disponibilidad de los estudiantes que en ese momento cursaban el grado 705 en la jornada de la mañana para llevar a cabo el presente estudio. 


\section{Referencias}

Alcaldía Mayor de Bogotá (2009). Conociendo la localidad de Fontibón: diagnóstico de los aspectos físicos, demográficos y socioeconómicos. Recupedo de http://www.sdp.gov.co/portal/page/portal/PortalSDP/ciudadania/Publicaciones\%20SDP/PublicacionesSDP/09fontibon.pdf

Azcuy, A. (2001). La educación de la sexualidad en el círculo infantil: una estrategia para su perfeccionamiento (Tesis para optar al título de doctor en Ciencias). Facultad de Biología, Universidad de La Habana, La Habana, Cuba.

Barragán, F. (2000). Programa de educación afectivo sexual, educación secundaria: sexualidad, educación sexual y género. Sevilla: Instituto Andaluz de la Mujer y Consejería de Educación y Ciencia.

Braidotti, R. (2004). Feminismo, diferencia sexual y subjetividad nómade. Barcelona: Gedisa.

Colegio Villemar el Carmen IED (2014). Manual de convivencia. Bogotá: Autor.

Conill, J. (2005). Alternativa metodológica para concebir el proceso de educación de la sexualidad de los niños con retraso mental (Tesis para optar al título de doctor en Ciencias). Facultad de Biología, Universidad de La Habana, La Habana, Cuba.

Giordan, A., y Vecchi, G. (1995). Los orígenes del saber: marco teórico (segunda edición). Sevilla: Díada Editora S.L.

González, A., y Castellanos B. (1998). Hacia una sexualidad responsable y feliz. La Habana: Editorial Pueblo y Educación.
González, L., Duque, M., Gladys, M., Ramírez, O., Otelo, R., y Marín, L. (2011). Proyecto de educación para la vida y el amor. Medellín: Institución Educativa el Salvador.

Insaurralde, E. (2013). Sexualidad, cuerpo y género: las representaciones de jóvenes pobres de la ciudad de La Plata (Tesis para optar al título de licenciada en Sociología). Departamento de Sociología, Universidad Nacional de La Plata, La Plata, Argentina.

Morgade, G. (2008). ¿Es posible abordar la "construcción social" del cuerpo sexuado en las ciencias naturales escolares? En E. Meinardi y A. Revel Chion (Comps.), Género y educación sexual en las escuelas (pp. 4-13). Buenos Aires: Compiladores.

Quijada, D. (2010). Percepciones que las mujeres tienen de su cuerpo y vivencia sexual (Tesis para optar al título de socióloga). Departamento de Sociología, Universidad de Chile, Santiago, Chile.

Ramírez, L., Arcila, A., Buriticá, L., y Castrillón, J. (2004). Paradigmas y modelos de investigación. Medellín: Fundación Universitaria Luis Amigó.

Salim, N., Araújo, N., y Gualda, D. (2010). Cuerpo y sexualidad: experiencias de puérperas. Revista Latinoamericana Enfermagem, 4(18), 10-18.

Tamayo, O. (2004). De las concepciones alternativas al cambio conceptual en la enseñanza y aprendizaje de las ciencias. Manizales: Universidad Autónoma de Manizales.

Vilanova, S., Mateos, M., y García, M. (2011). Las concepciones sobre la enseñanza y el aprendizaje en docentes universitarios de ciencias. Revista Iberoamericana de Educación Superior (RIES), 2(3), 53-75. 